\title{
Top Fifty Highly Cited Publications on the Internet of Things
}

\author{
P.K. Jayasekara ${ }^{1}$, K.S. Abu ${ }^{2}$
}

\begin{abstract}
The present study aimed at analyzing the publication pattern of highly cited research publications of Internet of Things. Web of Science citation database was used to extract data for the study. The top fifty highly cited publications were considered as the sample of this study. The data were analyzed based on publication year, document type, source title, time cited, usage count, authorship pattern, collaborative coefficient, research collaboration, and research areas. The findings revealed that majority of the publications were research articles and most of them were published in IEEE journals. Research articles written by multiple authors were more prominent than single-author publications. Researchers from USA and China preferred collaborative research and researchers from Italy preferred noninternational collaborative research. The researchers from developed western countries are highly engaging with research in Internet of Things. The most popular research areas under Internet of Things are computer science and telecommunication.
\end{abstract}

Keywords: Citation, Internet of Things, Scientometrics, Web of Science

\footnotetext{
1 Assistant Librarian, Main Library, University of Ruhuna. Email: pkjayasekara@gmail.com, (iD https://orcid.org/0000-0002-9033-1107

2 Ph.D. Research Scholar, Department of Library and Information Science, Bharathidasan University, Trichy, India. Email: abumutd@gmail.com, (iD https://orcid.org/0000-00025533-5110
}

Received: 21 March 2018, Accepted revised version: 8 May 2018. 


\section{Introduction}

The Internet has grown a lot in the recent years as more people make use of the web to access numerous content and to perform diverse tasks (Mishra et al., 2016). This has made the machines and devices to interact with each other in order to create a robust connection between them (Miorandi, Sicari, De Pellegrini, \& Chlamtac, 2012). These devices also connect the physical world with the cyber world, which eventually gave birth to the rise of cyberphysical systems (CPS) (Poovendran, 2010). Four technologies comprise CPS: automation of knowledge work, Internet of Things, advanced robotics, and autonomous/near-autonomous vehicles (Mishra et al., 2016). Internet of things (IoT) is "the combination of embedded technologies, wired and wireless communications and low cost sensing devices on the Internet" (Barnaghi \& Sheth, 2014). It came into reality when the Internet based service architecture used the concept of IoT in 1999 (Ashton, 2009).

Assessing the impact of publications based on citations determines the control of growth over a particular field (Bauer, Leydesdorff, \& Bornmann, 2016). As a result, research that have greater impact allows the analysis of the highly cited source, authors and institutions at the time of the study (Bornmann, 2014). Web of Science permits widespread citation search that allows in-depth investigation of academic and scientific sub-disciplines.

Web of Science (WoS) is one of the prominent citation database, which index and abstract the high impact journals. It provides access to the "most reliable, integrated, multidisciplinary research connected through linked content citation metrics from multiple sources within a single interface" (Clarivate Analytics, 2018). WoS Core Collection indexes include Science Citation Index Expanded (SCI-Expanded), Social Science Citation Index (SSCI), Arts \& Humanities Citation Index (A\&HCI) and Emerging Sources Citation Index (ESCI) (Clarivate Analytics, 2017d). Researchers can search the WoS database using various fields, some of the fields as follows; title, author, digital object identifier (DOI), publication year, publication name, document type and address.

Scientometrics is the "quantitative study of science, communication in science and science policy" (Hess, 1997, p.75). It helps to measure the 
research trends, the impact of research publications and authorship and collaboration patterns. Universities, governments, policymakers, researchers and librarians are using scientometrics to evaluate the research performance. Hence, the main aim of this study is to analyze the publication pattern of highly cited research publications in IoT using scientometric techniques.

\section{Research Objectives}

The main objective of this study is to ascertain the top 50 highly cited articles related to IoT in order to provide the researchers, scientists and practitioners a compilation of "citation classic" about IoT research. The other inter-linked objectives were to:

i. Analyze of publication characteristics such as year of publication, citation counts, source tiles, usage counts, core research areas

ii. Find out the authorship and collaboration patterns

\section{Literature Review}

According to the literature, numerous researchers have been engaged with analyzing highly cited publications about different research areas such as, Medicine (Jia, Ding, Wu, He, \& Ruan, 2015; Tao et al., 2012; Vielgut, Dauwe, Leithner, \& Holzer, 2017); Engineering (Mo, Fu, \& Ho, 2018); Environmental Science and Ecology (Parker, Allesina, \& Lortie, 2013); Horticulture (Kolle, Shankarappa, \& Ho, 2017); Library and Information Science (Levitt \& Thelwall, 2009) and Politics (Ho \& Hartley, 2017). However, scientometric studies on IoT are very rare (B. Gupta, Dhawan, \& Gupta, 2015; Mishra et al., 2016; Ruiz-Rosero et al., 2017)

In 2015, B. Gupta, Dhawan, \& Gupta, conducted a scientometrics examination of IoT research publications using Scopus database for a period of ten years (2005-2014). The results revealed that there were 6800 publications with an annual average growth rate of $98.63 \%$. China had the maximum publications globally and computer science was the core subject; further, analysis of journals, highly cited papers and organizations were discussed (Gupta et al., 2015). The analysis of highly cited publications by India in the field of computer science highlighted that India's share among the world output is very low, which is a real cause for concern. It is also suggested that multi-institutional collaboration is essential to publish high 
quality and impactful research in the field of computer science (Gupta \& Dhawan, 2017).

In 2016, Mishra and a group of researchers analyzed the research publications of IoT for a period of 16 years; they identified the top authors, key research areas and most influential works based on citations and page rank (Mishra et al., 2016). They have used the Scopus database to extract the data. Furthermore, Ruiz-Rosero et al. (2017) conducted a scientometric study on IoT research output using Scopus and WoS databases, considering publications over 15 years (2002-2016). They have analyzed the country affiliation of the first author, most published authors and research areas. According to their study, top research areas are applications, communication protocols, software processing, hardware and operating systems (RuizRosero et al., 2017).

Further, there are plethora of research explaining the technologies, vision and architecture of IoT but only a handful within the scientometrics context and none analyzes the highly cited publications of IoT. Hence, this study will help to identify the 50 highly cited research publications related to IoT and it will help researchers, scientists and practitioners to identify the extensively addressed IoT related research areas. In addition, this study will help in identification of research gaps and under-representing research areas that need to focus on future research.

\section{Methodology}

Search Strategy

The Web of science core collection was searched for the keyword "Internet of Things" or "IoT" on January 15, 2018. Phrase searching of keyword was used to ensure relevancy of publications. There were 1844 publications during the period of 29 years (1989-2017) and they were sorted according to their decreasing order of citations received for each publication. Consequently, a list of top 50 publications was selected with direct reference to the topic. 


\section{Data Analysis}

Each of the fifty articles was separately examined for their bibliographical details to create a list compiling of the title of publication, source titles, citation counts, usage counts, document types, research areas, authorship, collaborative coefficient, and collaborative pattern. All these details were tabulated separately and their impact, trends and patterns were analyzed.

\section{Results and Discussion}

Source Titles

Table 1 demonstrates the source wise distribution of highly cited publications in IoT. These top 50 highly cited publications are published in 27 journals. It is evidently noticed that publications with highest citations are mostly published in IEEE journals (24 out of 50). 'Computer Networks', 'IEEE Internet Computing' and 'IEEE Transactions' has the maximum number of publications with four per each.

\section{Year wise Distribution of Publications}

Figure 1 illustrates the year wise distribution of considered publications on the IoT. According to Figure 1, highly cited publications on IoT has a very short history. The first publication was in 2004. The highest number of publications were from the year 2011 with 13 publications followed by the year 2014 with 12 publications. There were six publications per year for the years 2012 and 2013.

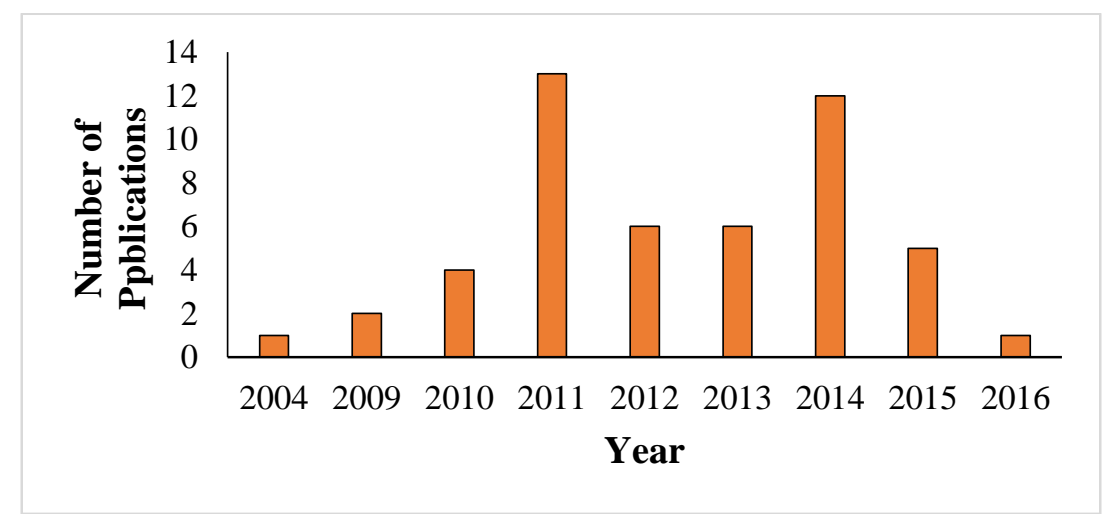

Figure 1. Publication year vs number of publications 
Table 1. Published journal

\begin{tabular}{ll}
\hline Journal & No of \\
& publications \\
\hline Computer Networks & 4 \\
IEEE Internet Computing & 4 \\
IEEE Transactions on Industrial Informatics & 4 \\
IEEE Communications Magazine & 3 \\
IEEE Communications Surveys and Tutorials & 3 \\
IEEE Internet of Things Journal & 3 \\
Journal of Network and Computer Applications & 3 \\
Future Generation Computer Systems & 2 \\
IEEE Communications Letters & 2 \\
IEEE Wireless Communications & 2 \\
Information Systems Frontiers & 2 \\
Personal and Ubiquitous Computing & 2 \\
Wireless Personal Communications & 2 \\
Ad Hoc Networks & 1 \\
Computer & 1 \\
Computer Communications & 1 \\
Computer-Aided Design & 1 \\
Computers \& Electrical Engineering & 1 \\
IEEE Access & 1 \\
IEEE Network & 1 \\
IEEE Transactions on Services Computing & 1 \\
International Journal of Communication Systems & 1 \\
International Journal on Semantic Web & 1 \\
Information Systems & 1 \\
Journal of Computer Science and Technology & 1 \\
Scientific American & 1 \\
Transactions on Emerging Telecommunications & 1 \\
Technologies & \\
Wireless Networks & 1 \\
\hline
\end{tabular}




\section{Document Type}

According to the WoS database, the top cited research on IoT has been published as articles, article; proceeding paper, editorial material and reviews (Figure 2). Among them, the large majority (88\%) of research were published as articles.

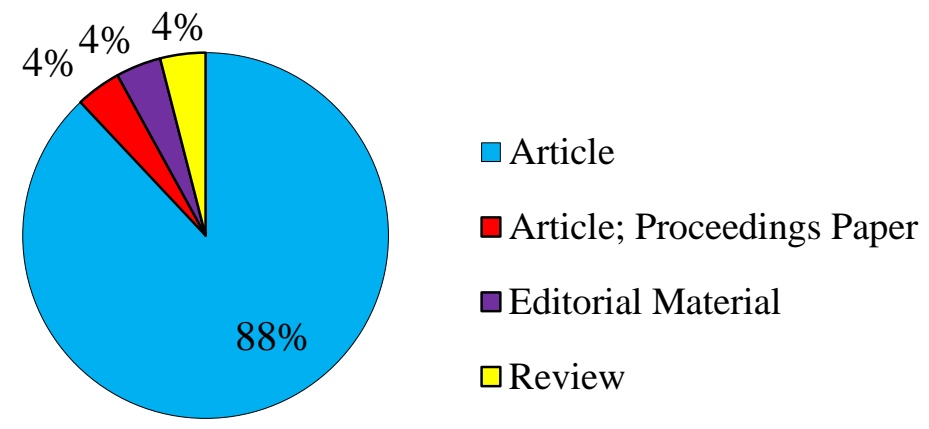

Figure 2. Document type of publications

\section{Time Cited}

The Time Cited value give the "number of articles in the database that cite the current article" (Clarivate Analytics, 2017a). The number of citations received by considered articles are in the range from 2643 to 73 (Figure 3). Top five articles received Time Cited values 2643, 1274, 654, 436 and 397 respectively.

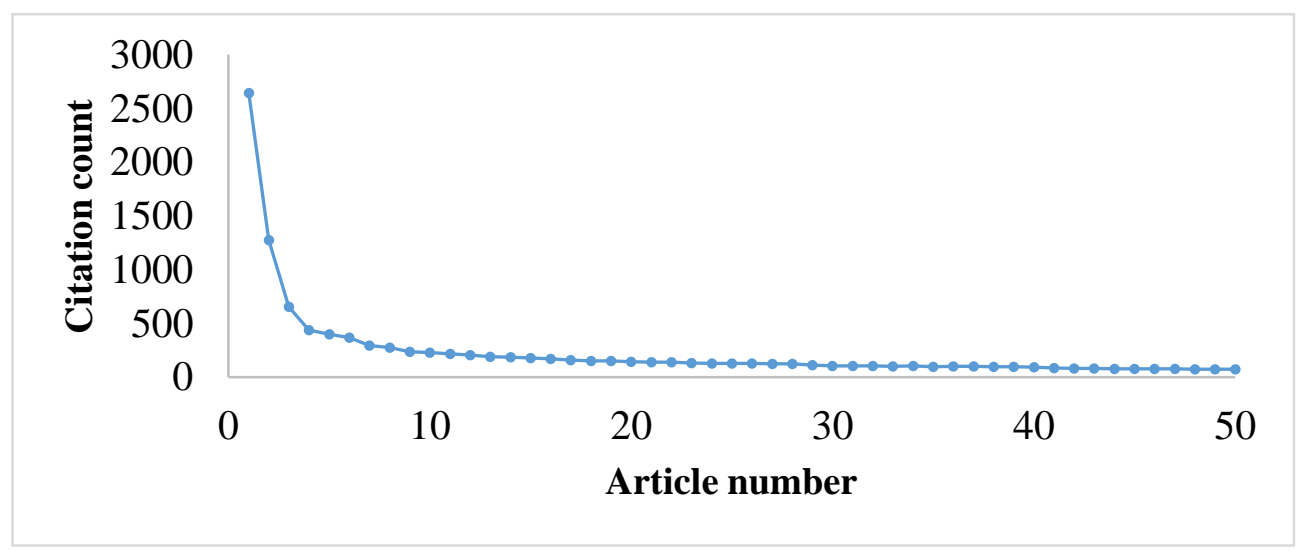

Figure 3. Time cited 
Table 2 demonstrates the details of top five articles with highest citation count. An article titled 'The Internet of Things: A survey' authored by Luigi Atzori, Antonio Iera and Giacomo Marabito, published in Computer Networks journal in 2010 received the highest Time Cited value 2643. A research titled 'Internet of Things (IoT): A vision, architectural elements, and future directions' authored by J. Gubbi, R. Buyya, S. Marusic and M. Palaniswami in 2013 received the second place with 1274 total citations.

Table 2. Top five articles with highest citations

\begin{tabular}{|c|c|c|c|c|}
\hline No & Title & Journal & $\begin{array}{l}\text { Published } \\
\text { year }\end{array}$ & $\begin{array}{l}\text { Time } \\
\text { cited }\end{array}$ \\
\hline 1 & $\begin{array}{l}\text { The Internet of Things: } \\
\text { A survey }\end{array}$ & $\begin{array}{l}\text { Computer } \\
\text { Networks }\end{array}$ & 2010 & 2643 \\
\hline 2 & $\begin{array}{l}\text { Internet of Things (IoT): } \\
\text { A vision, architectural } \\
\text { elements, and future } \\
\text { directions } \\
\text { Internet of things: }\end{array}$ & $\begin{array}{l}\text { Future Generation } \\
\text { Computer } \\
\text { Systems }\end{array}$ & 2013 & 1274 \\
\hline 3 & $\begin{array}{l}\text { Vision, applications and } \\
\text { research challenges }\end{array}$ & Ad Hoc Networks & 2012 & 654 \\
\hline 4 & $\begin{array}{l}\text { Internet of Things for } \\
\text { Smart Cities }\end{array}$ & $\begin{array}{l}\text { IEEE Internet of } \\
\text { Things Journal }\end{array}$ & 2014 & 436 \\
\hline 5 & $\begin{array}{l}\text { Smart Objects as } \\
\text { Building Blocks for the } \\
\text { Internet of Things }\end{array}$ & $\begin{array}{l}\text { IEEE Internet } \\
\text { Computing }\end{array}$ & 2010 & 397 \\
\hline
\end{tabular}

\section{Usage Count}

The usage count of an article reflects the number of times that a full-text article has been accessed or saved within given period (Clarivate Analytics, 2017c). The WoS database measures usage count in two ways; usage count in last 180 days and usage count since 2013. The usage count in last 180 days for top cited articles vary within 227 and 1 (Figure 4). The first two articles with top Time Cited 'The Internet of Things: A survey' in Computer Networks in 2010' and 'Internet of Things (IoT): A vision, architectural elements, and future directions' in Future Generation Computer Systems in 
2013' received the top two usage counts in last 180 days; 227 and 212 respectively.

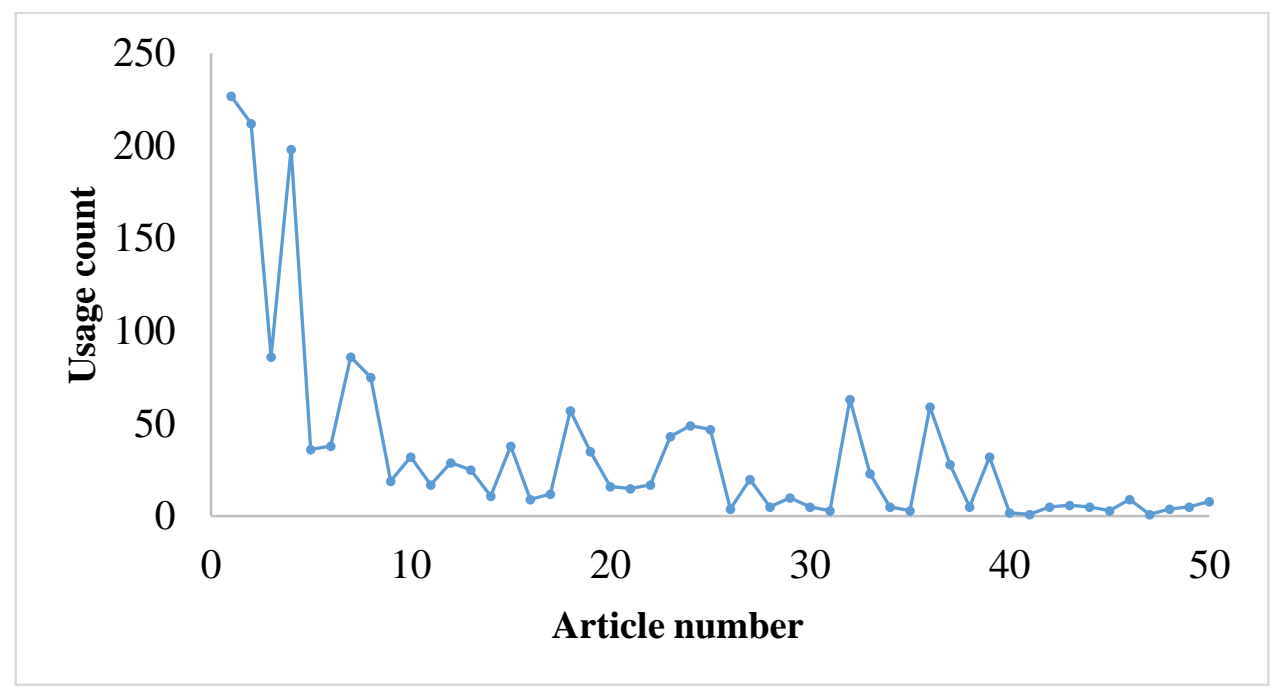

Figure 4. Usage count in last 180 days

Figure 5 shows the usage count since 2013. The usage counts received by the considered articles since 2013 are range from 1242 to 32. Interestingly, the article with second most time cited titled 'Internet of Things (IoT): A vision, architectural elements, and future directions' published in Future Generation Computer Systems in 2013 gained the highest usage count (1242) since 2013. The publication titled 'Internet of things: Vision, applications and research challenges' published in Ad Hoc Networks in 2012 received the second highest usage count since 2013 which is 661 usage count. The article with the highest time cited got third most usage count (518).

\section{Authorship}

Research publications written by multiple authors were more prominent than single-author publications. There were only five out of 50 single author publications. There were 15 four-author publications followed by 13, threeauthor publications. Furthermore, the research publication titled 'Enabling Smart Cities through a Cognitive Management Framework for the Internet of Things' published in IEEE Communication Magazine in 2013 was authored by 10 authors. 


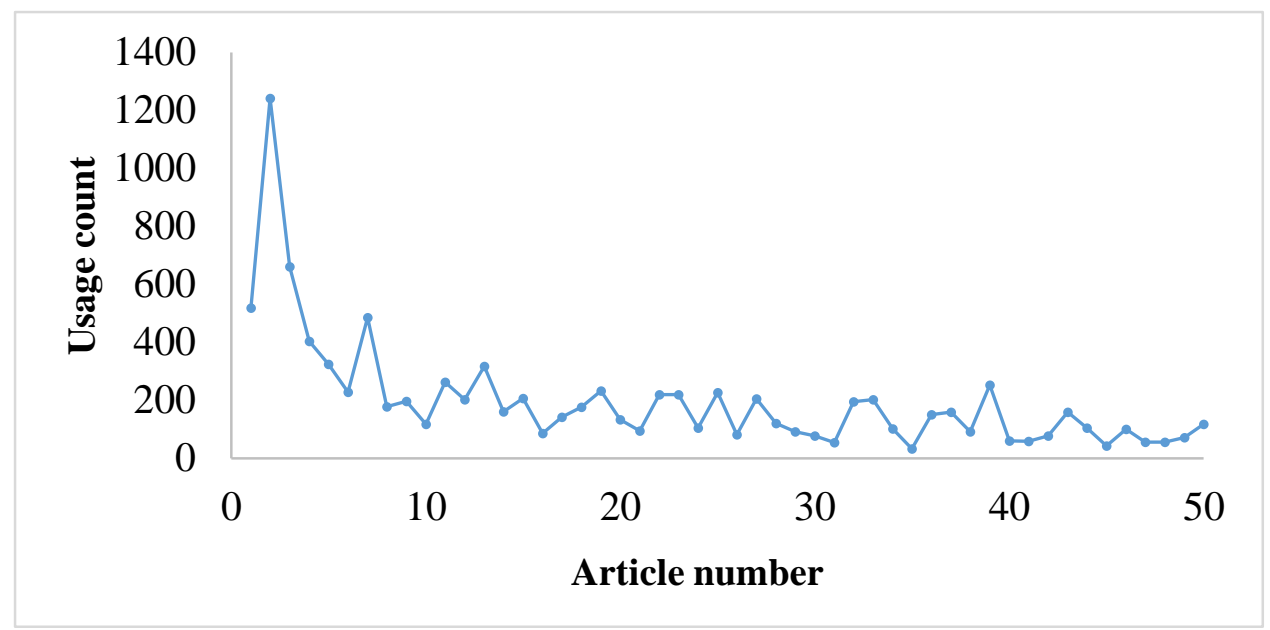

Figure 5. Usage count since 2013

Collaborative Coefficient

Collaborative coefficient was calculated using the Equation 1 developed by Ajiferuke, Burell, \& Tague in 1988.

Where:

$$
\mathrm{CC}=1-\frac{\sum_{j=1}^{k}\left(\frac{1}{j}\right) f_{k}}{N}
$$

CC - Collaborative coefficient

$\mathrm{N}$ - Total number of research publications in a discipline within certain period of time

$\mathrm{k}$ - the greatest number of authors per paper in a discipline

$f_{j}$ - the number of $j$ authored research papers published in a discipline within a certain period of time

Collaborative coefficient (CC) is a value between zero and one. If single author articles are dominating CC is close to zero and if jointly authored articles are dominating CC is close to one. Hence, higher the CC value there are more multi or mega authored papers (Ajiferuke et al., 1988). 
According to the considered publications in this study, $\mathrm{N}$ is equal to 50 and $\mathrm{k}$ equal to 10 . Hence, CC for the present study is 0.66 , which indicates majority of top cited articles are multi-authored.

\section{International Collaboration}

The collaborative pattern of publications indicates that, majority of researchers prefer collaborating with their colleagues when compared to international collaboration (Table 3). Meanwhile, there were 17 publications with two countries collaboration, seven publications with collaboration between three countries and a single publication with collaboration between four countries. The research article titled 'A Survey on Facilities for Experimental Internet of Things Research' published in IEEE Communications Magazine in 2011 was a research product of four countries collaboration between England, USA, Italy and Germany.

\section{Table 3. International collaboration}

\begin{tabular}{ll}
\hline Type of collaboration & Number of publications \\
\hline Non-international collaborative research & 25 \\
Two countries collaboration & 17 \\
Three countries collaboration & 7 \\
Four countries collaboration & 1 \\
\hline
\end{tabular}

Countries with non-collaborative research publications with researchers outside their country is also important. There were eight research publications from Italy followed by four from Australia and USA respectively. England, Germany, India and Switzerland had a single noncollaborative publication from each country.

Figure 6 illustrates the research collaboration between two countries. There were two publications with collaboration between USA and China. Furthermore, USA and China were the countries with highest collaborations, which have collaborations with five different countries. England and Germany have collaborations with four countries and three countries respectively. 


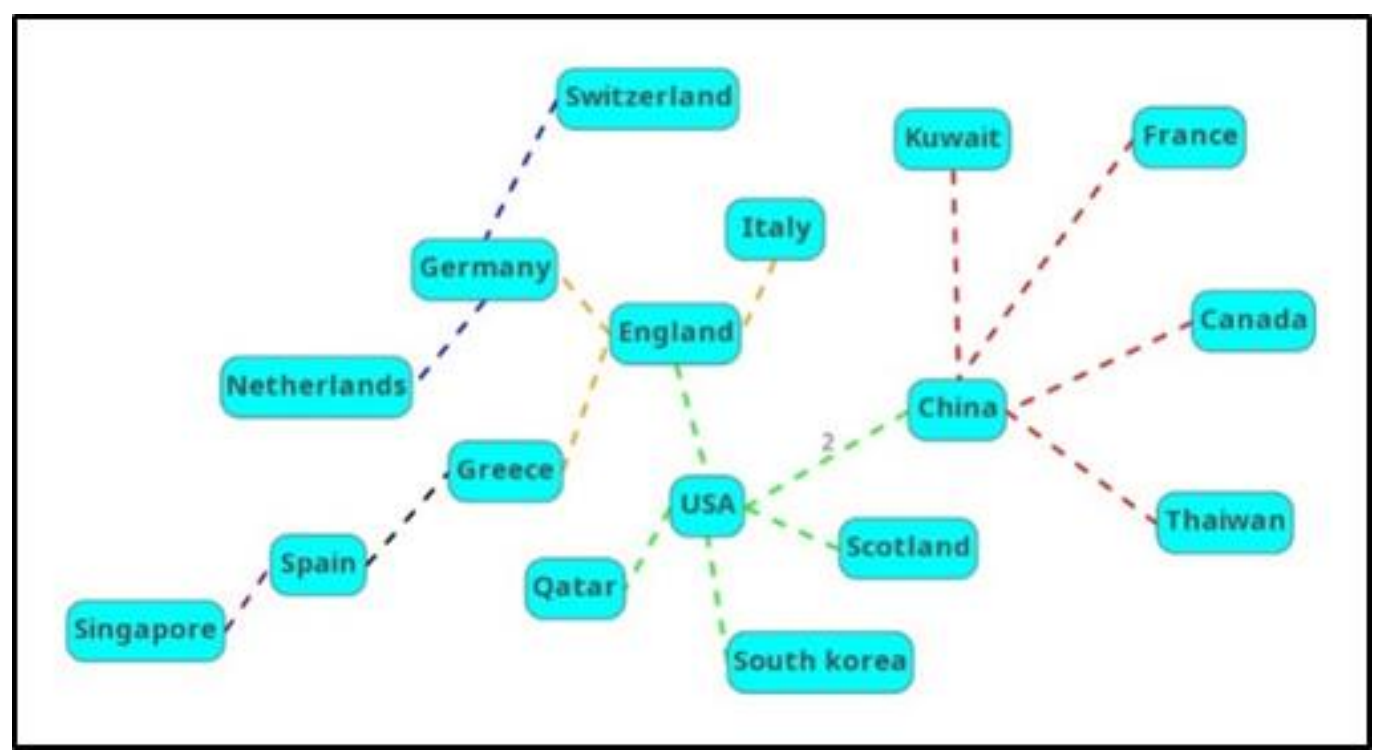

Figure 6. Two countries collaboration

Research Areas

"Research areas constitute a subject categorization scheme that is shared by all WoS product databases" (Clarivate Analytics, 2017b). The following word cloud (Figure 7) illustrates the research areas covered by top cited articles.

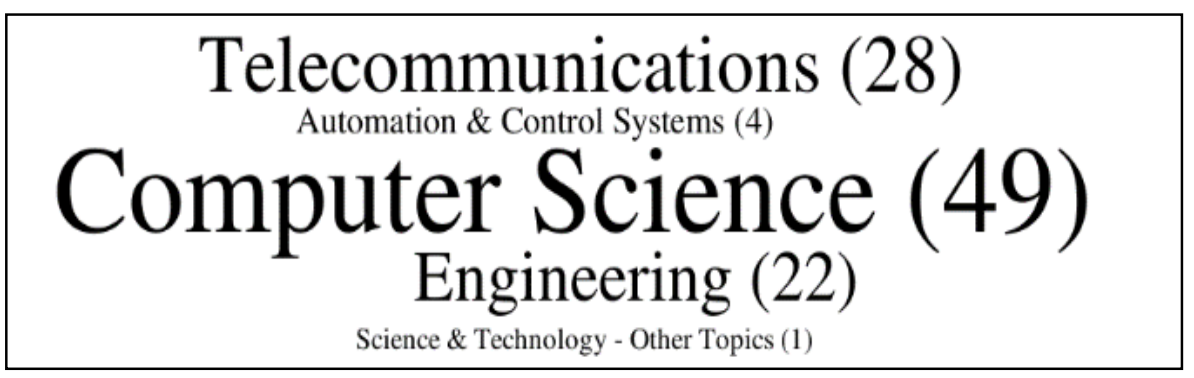

Figure 7. Research areas

The top cited IoT publications could divide into main five research areas; computer science, telecommunications, engineering, automation \& control systems and science \& technology-other topics (Figure 7). Among them, 49 publications were related to computer science. There were 28 publications related to telecommunications followed by 22 publications related to engineering. 


\section{WoS Categories}

Every journal and book covered by WoS Core Collection has been categorized into at least one subject category (Web of Science, 2017). WoS categories provide more in-depth classification than research areas (Figure 8). According to WoS categories, the highest number of publications (28) were related to telecommunications followed by computer science, information system (22) and engineering, electrical \& electronic (18).

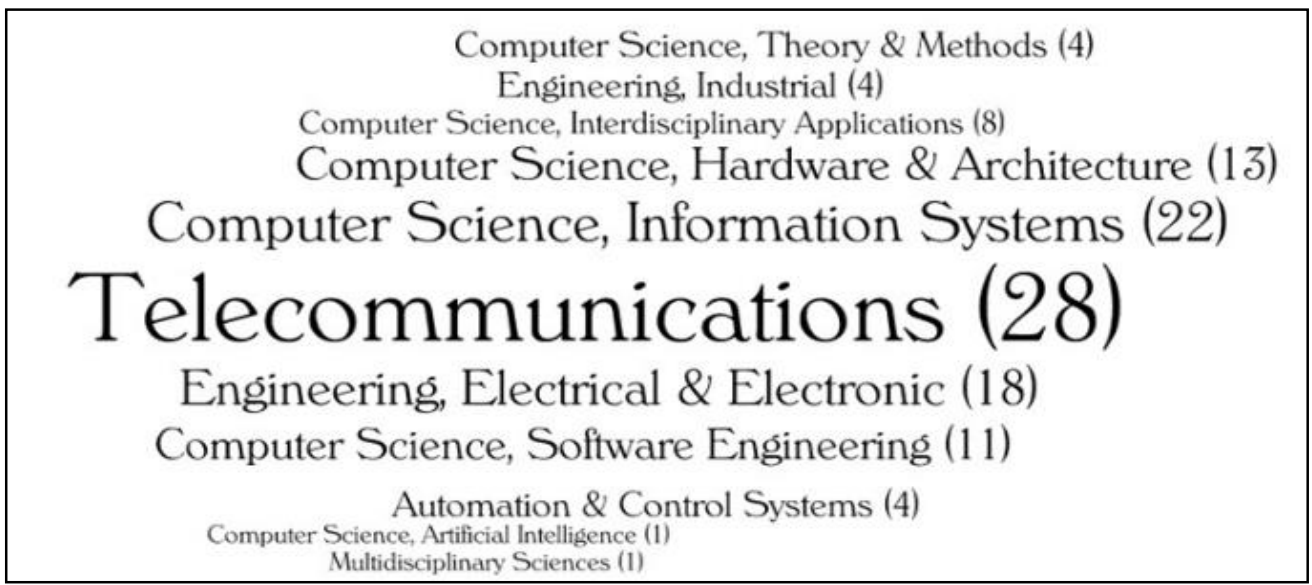

\section{Figure 8. WoS categories}

\section{Conclusion}

This study aimed at analyzing the highly cited papers related to IoT in order to deliver the researchers, scientists and other practitioners to create a list of citation classic to read about the widely accepted scientific research related to IoT. According to results, year 2011 and 2014 were identified as the years with the highest number of highly cited publications. Research articles were the most popular way of presenting research findings. Based on the publication pattern, most of the researchers from the USA and China like to do collaborative research with researchers from other countries. The researchers from developed western countries are highly engaging in IoT research.

Results of CC indicated that researchers like to work as a group than individually in publishing articles. Most of IoT research are mainly coming under computer science field followed by telecommunication. Most of top cited IoT research are computer-based studies. 
This kind of bibliometric study gives a portrait of the commonly cited articles in their specific field. Although citation counts can be manipulated by means of self-citations, sub-publications (Ahmad, Evangelopoulos, Abbasian, Röder, \& Kohl, 2014) and citing poor research (Nieminen, Carpenter, Rucker, \& Schumacher, 2006). Despite of these limitations, still it is one of the best ways to assess the impact of scientific research (Ahmad et al., 2014) .

This research will help the researchers and other practitioners with a reading list of most influential articles related to IoT which may provide as a base for further discussions and a foundation for future research.

\section{References}

Ahmad, S. S., Evangelopoulos, D. S., Abbasian, M., Röder, C., \& Kohl, S. (2014). The hundred most-cited publications in orthopaedic knee research. Journal of Bone and Joint Surgery - American Volume, 96(22). https://doi.org/10.2106/JBJS.N.00029

Ajiferuke, I., Burell, Q., \& Tague, J. (1988). Collaborative coefficient: A single measure of the degree of collaboration in research. Scientometrics, 14(5-6), 421-433. https://doi.org/10.1007/BF02017100

Ashton, K. (2009). That "Internet of Things" thing. RFiD Journal, 22, 97114. https://doi.org/10.1145/2967977

Barnaghi, P., \& Sheth, A. (2014). The Internet of Things: The story so far. Retrieved from https://iot.ieee.org/newsletter/september-2014/theinternet-of-things-the-story-so-far.html

Bauer J, Leydesdorff L, \& Bornmann L. (2016). Highly-cited papers in Library and Information Science (LIS): Authors, institutions, and network structures. Journal of the Association for Information Science and Technology, 67(12), 3095-3100

Bornmann, L. (2014). How are excellent (highly cited) papers defined in bibliometrics? A quantitative analysis of the literature. Research Evaluation, 23(2), 166-173. https://doi.org/10.1093/reseval/rvu002

Clarivate Analytics. (2017a). Full record. Retrieved from http://images.webofknowledge.com/WOKRS5251R3/help/WOS/hp_full_record.html 
Clarivate Analytics. (2017b). Research areas (categories/classification). Retrieved from http://images.webofknowledge.com/WOKRS5251R3/help/WOS/hp_res earch_areas_easca.html

Clarivate Analytics. (2017c). Usage count. Retrieved from http://images.webofknowledge.com/WOKRS5251R3/help/WOS/hp_us age_score.html

Clarivate Analytics. (2017d). Web of Science core collection indexes. Retrieved from https://images.webofknowledge.com/images/help/WOS/hp_database.html

Clarivate Analytics. (2018). Web of Science. Retrieved from http://login.webofknowledge.com/error/Error?Error=IPError\&PathInfo $=\% 2 \mathrm{~F} \&$ RouterURL=http\%3A\%2F\%2Fwww.webofknowledge.com $\% 2$ F\&Domain=.webofknowledge.com\&Src $=$ IP\&Alias=WOK5

Gupta, B., Dhawan, S., \& Gupta, R. (2015). Internet of Things: A scientometric assessment of global output, 2005-2014. Journal of Scientometric Research, 4(2), 104. https://doi.org/10.4103/23200057.167248

Gupta, B. M., \& Dhawan, S. M. (2017). Highly cited publications output by India in Computer Science 1996-15: A Scientometric Assessment. Journal of Scientometric Research, 6(2), 74-85.

Hess, D. J. (1997). Science studies: An advanced introduction. New York: University Press.

Ho, Y. S., \& Hartley, J. (2017). Highly cited publications in world war II: A bibliometric analysis. Scientometrics, 110(2), 1065-1075. https://doi.org/10.1007/s11192-016-2199-4

Jia, Z., Ding, F., Wu, Y., He, Q., \& Ruan, D. (2015). The 50 most-cited articles in orthopaedic surgery from mainland China. Clinical Orthopaedics and Related Research, 473(7), 2423-2430. https://doi.org/10.1007/s11999-015-4132-1

Kolle, S. R., Shankarappa, T. H., \& Ho, Y. S. (2017). Highly cited articles in Science Citation Index Expanded-subject category of horticulture: 
A bibliometric analysis. Erwerbs-Obstbau, 59(2), 133-145. https://doi.org/10.1007/s10341-016-0308-4

Levitt, J. M., \& Thelwall, M. (2009). The most highly cited library and information Science articles: Interdisciplinarity, first authors and citation patterns. Scientometrics, 78(1), 45-67. https://doi.org/10.1007/s11192-007-1927-1

Miorandi, D., Sicari, S., De Pellegrini, F., \& Chlamtac, I. (2012). Internet of things: Vision, applications and research challenges. Ad Hoc Networks, 10(7), 1497-1516. https://doi.org/10.1016/j.adhoc.2012.02.016

Mishra, D., Gunasekaran, A., Childe, S. J., Papadopoulos, T., Dubey, R., \& Wamba, S. (2016). Vision, applications and future challenges of Internet of Things: A bibliometric study of the recent literature. Industrial Management \& Data Systems, 116(7), 1331-1355. https://doi.org/https://doi.org/10.1108/IMDS-11-2015-0478

Mo, Z., Fu, H. Z., \& Ho, Y. S. (2018). Highly cited articles in wind tunnelrelated research: a bibliometric analysis. Environmental Science and Pollution Research, 1-13. https://doi.org/10.1007/s11356-018-1766-z

Nieminen, P., Carpenter, J., Rucker, G., \& Schumacher, M. (2006). The relationship between quality of research and citation frequency. BMC Medical Research Methodology, 6(1), 42. https://doi.org/10.1186/14712288-6-42

Parker, J. N., Allesina, S., \& Lortie, C. J. (2013). Characterizing a scientific elite (B): publication and citation patterns of the most highly cited scientists in environmental science and ecology. Scientometrics, 94(2), 469-480. https://doi.org/10.1007/s11192-012-0859-6

Poovendran, R. (2010). Cyber-physical systems: Close encounters between two parallel worlds. In Proceedings of the IEEE (Vol. 98, pp. 13631366). https://doi.org/10.1109/JPROC.2010.2050377

Ruiz-Rosero, J., Ramirez-Gonzalez, G., Williams, J., Liu, H., Khanna, R., \& Pisharody, G. (2017). Internet of Things: A scientometric review. Symmetry, 9(12), 301. https://doi.org/10.3390/sym9120301

Tao, T., Zhao, X., Lou, J., Bo, L., Wang, F., Li, J., \& Deng, X. (2012). The top cited clinical research articles on sepsis: A bibliometric analysis. 
Critical Care, 16(3). https://doi.org/10.1186/cc11401

Vielgut, I., Dauwe, J., Leithner, A., \& Holzer, L. A. (2017). The fifty highest cited papers in anterior cruciate ligament injury. International Orthopaedics, 41(7), 1405-1412. https://doi.org/10.1007/s00264-0173513-3

Web of Science. (2017). Web of Science categories. Retrieved from http://images.webofknowledge.com/WOKRS5251R3/help/WOS/hp_su bject_category_terms_tasca.html 